\title{
VALORAÇÃO DE USINA TERMELÉTRICA DE BIOMASSA: UM ESTUDO DE CASO
}

\author{
Thaís Cristina de Souza Nogueira" \\ David Ferreira Lopes Santos* \\ Santiago Valcacer Rodrigues ${ }^{* * *}$
}

\begin{abstract}
RESUMO: Os objetivos deste estudo são valorar uma planta termelétrica, baseada em biomassa, associada a um grupo sucroenergético e avaliar sua capacidade de criação de valor para os acionistas. A geração de energia elétrica a partir da biomassa é a terceira fonte de energia elétrica do Brasil e aquela que apresentou na última década o maior crescimento marginal. A pesquisa decorreu a partir de um estudo de caso com fins exploratórios e descritivos durante o ano de 2014. A planta alvo está localizada no interior do Estado de São Paulo. As ferramentas para valorar este investimento foram o Fluxo de Caixa Descontado (FCD) e a Teoria por Opções Reais (TOR) com a opção de abandono do investimento pelo valor da dívida. Os resultados demonstraram que a TOR foi mais eficiente e robusta para determinar o valor do investimento em $\mathrm{R} \$ 69,346$ milhões, pois considerou a volatilidade do preço da energia.
\end{abstract}

PALAVRAS-CHAVE: Setor sucroenergético; Fluxo de caixa descontado; Teoria de opções reais.

\section{CASE STUDY FOR THE VALORIZATION OF A BIOMASS THERMO- ELECTRIC PLANT}

ABSTRACT: Current study valorizes a biomass-based thermo-electric plant associated to sugarcane and power group and evaluates its capacity in the establishment of value for shareholders. The production of biomass-based electric energy is the third electric energy source in Brazil, with the highest growth during the last ten years. Research is a case study featuring exploratory and descriptive aims in 2014. The target plant lies in the hinterland of the state of São Paulo. Assessment tools

Graduada em Administração de Empresas pela Faculdade de Ciências Agrárias e Veterinárias, Universidade Estadual Paulista "Júlio de Mesquita Filho" (UNESP), Brasil.

** Docente Assistente Doutor em regime RDIDP na Universidade Estadual Paulista "Júlio de Mesquita Filho" (UNESP), junto ao Departamento de Economia, Administração e Educação da Faculdade de Ciências Agrárias e Veterinárias, Brasil. E-mail: david.lopes@fcav.unesp.br

${ }^{* * *}$ Mestre em Administração de Empresas pela Universidade de Fortaleza (UNIFOR), Brasil. 
comprised Discounted Cash Flow and the Theory of True Options with the option of investment quittance by debt value. Results show that TTO was more efficient and robust to calculate investment value at $R \$ 69.346$ million since the volatility of energy prices were taken into account.

KEY WORDS: Sugarcane sector; Discounted cash flow; Theory of true options.

\section{INTRODUÇÃO}

A cadeia da cana-de-açúcar no Brasil foi alçada ao nível estratégico na matriz energética em função do seu potencial e impacto na produção agrícola do açúcar da cana, na produção de combustível, por meio do etanol anidro e hidratado e mais recentemente na produção de energia elétrica (SPETIC; MARQUEZ; KOZAK, 2012).

A produção em larga escala de biocombustíveis no Brasil ocorreu na década de 1970 com o programa do governo federal "Pró-Alcool" (FIGUEIRA; BORGES; SANTOS, 2013). Este mercado foi potencializado com o desenvolvimento da tecnologia de motores automotivos flexfuel na última década (UNICA, 2012).

A geração de energia elétrica pelo bagaço da cana-de-açúcar foi a principal inovação neste setor nos últimos anos, transformando a tradicional atividade 'sucroalcooleira' em 'sucroenergética' (SANTOS et al., 2015).

Políticas públicas foram empreendidas para fomentar o investimento em termelétricas, com vistas à diversificação da matriz energética brasileira (UNICA, 2012). Em 2012, as termelétricas foram responsáveis por $27 \%$ da produção de energia elétrica do Brasil, sendo a energia hidrelétrica a líder na geração de energia com 66\% (ANEEL, 2012).

Diante deste contexto, esta pesquisa tem como objetivos valorar uma planta termelétrica, baseada em biomassa, associada a um grupo sucroenergético e avaliar sua capacidade de criação de valor para os acionistas.

Essa preocupação assumiu a agenda do setor, pois apesar da importância estratégica desta fonte de energia renovável, e da oportunidade de diversificação de mercados com outro produto; a geração de energia elétrica em plantas térmicas associadas a usinas/destilarias de açúcar e etanol exige elevados investimentos, domínio de tecnologia distinta aos demais produtos e atuação em outro segmento de mercado com aspectos regulatórios específicos, além da volatilidade do preço da 
energia junto aos leilões e mercado spot (BASTIAN-PINTO; BRANDÃO, 2007).

Portanto, postula-se valorar uma planta térmica a partir do uso da Teoria de Opções Reais (TOR) como instrumento teórico-metodológico. O uso da TOR para avaliar ativos reais é crescente no meio empresarial (CHUNG et al., 2013; GRAHAM; HARVEY, 2001), sendo inclusive utilizada para avaliar projetos de geração de energia renovável (BASTIAN-PINTO; BRANDÃO, 2007; CESEÑA; MUTALE; RIVAS-DÁVALOS, 2013; KALLIO; KUULA; OINONEN, 2012; LIN; WESSEH JR, 2013; MILANESI, 2014; MUSSHOFF, 2012; SANTOS et al., 2014; SANTOS; REBELATO; RODRIGUES, 2012; WANG; CAI; DAI, 2014). No entanto, a opção de abandono em termelétricas de biomassa não foi valorada o que permitirá analisar a extensão de aplicação da TOR neste contexto, assim como evidenciar para investidores e empresários o processo de valoração de um ativo complexo como uma planta termelétrica.

A avaliação de investimentos por opções reais é empregada na presença de flexibilidade gerencial em alterar o curso do projeto mediante a identificação, a prio$r i$, de incertezas (CHUNG et al., 2013). Essa técnica ganhou espaço nas avaliações de criação de valor das empresas, em função das limitações do método baseado no Fluxo de Caixa Descontado (FCD) (PINDYCK, 1993).

Para alcançar os objetivos propostos, este estudo foi organizado com mais três seções. A segunda seção apresenta as duas principais técnicas de valoração empresarial o FCD e a TOR. A terceira seção traz os materiais e métodos utilizados para construção do estudo de caso. A quarta seção apresenta e discute os resultados alcançados e, finalmente, a quinta seção aponta as considerações finais do artigo. As referências utilizadas são elencadas na sequência e há um Apêndice com todas as fórmulas utilizadas no processo de valoração.

\section{REFERENCIAL TEÓRICO}

\subsection{TÉCNICAS DE VALORAÇÃO}

Para Damodaran (2010), a avaliação por Fluxo de Caixa Descontado (FCD) é a base para todas as outras abordagens sobre o assunto, pois garante, ao mesmo tempo, o valor do dinheiro no tempo, o volume da riqueza agregada e a verificação 
do retorno.

De acordo com o FCD o valor de um ativo é igual ao valor presente dos fluxos de caixa futuro (GRAHAM; HARVEY, 2001). Cada ativo apresenta um fluxo de caixa, que varia de acordo com os seus valores e suas taxas de desconto, as quais refletem o risco do investimento (LIN; WESSEH JR., 2013). Assim, Damodaran (2010) apresenta o cálculo do valor de um ativo por meio da Fórmula (1):

$$
\text { Valor }=\sum_{t=1}^{t=n} \frac{C F_{t}}{(1+r)^{t}}
$$

Em que $n$ é a Vida Útil do Ativo; $\mathrm{CF}_{\mathrm{t}}$ o Fluxo de Caixa no Período t e r é a Taxa de Desconto Refletindo o Risco Inerente aos Fluxos de Caixa Estimados.

O FCD é o método de avaliação da riqueza econômica, pois se baseia nos Fluxos de Caixa estimados e descontados a uma taxa que reflete o custo de oportunidade da empresa (FERNANDES; CUNHA; FERREIRA, 2011).

Atualmente, a Teoria das Opções Reais (TOR) vem mudando os conceitos da tradicional estratégia corporativa e dos orçamentos de capital, enfatizando a capacidade de flexibilidade operacional em condições de incerteza (CESEÑA; MUTALE; RIVAS-DÁVALOS, 2013; CHUNG et al., 2013).

O desenvolvimento das opções reais se dá na limitação do FCD (CESEÑA; MUTALE, 2011). O FCD limita-se apenas às informações expostas no momento da elaboração do projeto, visto que muitas informações não estão disponíveis no momento inicial quando não se dispõe de todas as informações que cercam o projeto, com efeito, admite-se que os gestores não têm condições de interferir na evolução dos investimentos após o seu início (SANTOS; PAMPLONA, 2005).

Copeland e Antikarov (2001) ressaltam que o valor das opções reais depende de algumas variáveis, sendo elas: valor do ativo subjacente sujeito a risco, preço de exercício, prazo de vencimento da opção, desvio-padrão do ativo subjacente sujeito a risco e as taxas de juros livre de risco ao longo da vida da opção.

Para Santos, Rebelato e Rodrigues (2012), opção é o direito de comprar ou vender o ativo-objeto em questão, esse direito pode ser exercido até o prazo de vencimento da opção.

Nestas condições, a TOR se apresenta como um instrumento mais robusto 
para avaliar projetos de investimento com maiores níveis de incertezas e que permitem a flexibilidade gerencial junto ao investimento (CESEÑA; MUTALE; RIVAS-DÁVALOS, 2013; CHUNG et al., 2013; SANTOS; REBELATO; RODRIGUES, 2012; SANTOS et al., 2014; WANG; CAI; DIA, 2014).

Mesmo com as limitações da abordagem do FCD, a TOR não o descarta, ao contrário, pois depende da construção do fluxo de caixa dos investimentos previstos e o desconto destes à taxa de risco utilizada pela empresa ou calculada pela abordagem tradicional do Capital Asset Pricing Modelling (CAPM) (GRULLON; LYANDRES; ZHDANOV, 2012; KALLIO, KUULA; OINONEN, 2012).

\section{MATERIAL E MÉTODO}

O presente estudo trata-se de uma pesquisa de natureza exploratória, com caráter descritivo, a partir de uma abordagem qualitativa e quantitativa com o uso do método estudo de caso.

O uso do estudo de caso como abordagem metodológica deve-se à natureza do fenômeno que ocorre de fato no âmbito da organização, cujo acesso as informações e o contexto do investimento se dá mediante a proximidade da relação entre pesquisador e objeto, o que permite a expansão da abordagem teórica no caso a ser avaliado (YIN, 2005).

As técnicas de pesquisa utilizadas no estudo de caso foram: i) análise de documentos internos da empresa; ii) análise das demonstrações financeiras padronizadas (auditadas) do grupo econômico; iii) visita supervisionada na área contábil para conhecimento do processo e observação das práticas de contabilização dos dados financeiros; essas técnicas estão alinhadas com os protocolos previstos em Yin (2005) para aumentar a confiabilidade do estudo de caso. O período que transcorreu a pesquisa empírica decorreu entre os meses de março/2014 a outubro/2014.

Para a prospecção do fluxo de caixa utilizaram-se todas as informações financeiras disponíveis da termelétrica entre 2008 e 2013, e como se trata de um investimento recente pela empresa utilizou-se toda fonte de informação disponível.

Além dos dados da termelétrica investigada, foram utilizados índices de 
mercado identificados em empresas estabelecidas no segmento de energia renovável (CPFL Renovável, Desenvix, Elektro e Tractebel). Os índices utilizados foram: Crescimento Líquido do Imobilizado e o Beta, pois a empresa não tinha histórico e informações para a construção destas informações, em função do estágio inicial do investimento. Além destes benchmarks, foi utilizada a série histórica do preço da energia junto ao domínio eletrônico da ANEEL.

A principal incerteza encontrada neste investimento foi a volatilidade dos preços de energia elétrica, que podem oscilar dependendo do cenário e de fatores externos à empresa.

Em atendimento a exigência da empresa, sua razão social ou informações que possam identificá-la foram suprimidas, sem, contudo, inviabilizar a consecução do objetivo desta pesquisa.

O modelo de avaliação das opções utilizado neste estudo é o Modelo Binomial, proposto por Cox, Ross e Rubinstein (1979). O modelo binomial é baseado numa fórmula simples do processo de precificação de ativos, onde o preço do ativo (S) pode se deslocar para outros dois preços $\left(\mathrm{S}_{u}\right.$ e $\left.\mathrm{S}_{d}\right)$, conforme a volatilidade esperada (CESEÑA e MUTALE, 2011; MUSSHOFF, 2012; SANTOS et al., 2014; WANG, CAI, DAI, 2014). A Figura 1 ilustra o processo binominal.

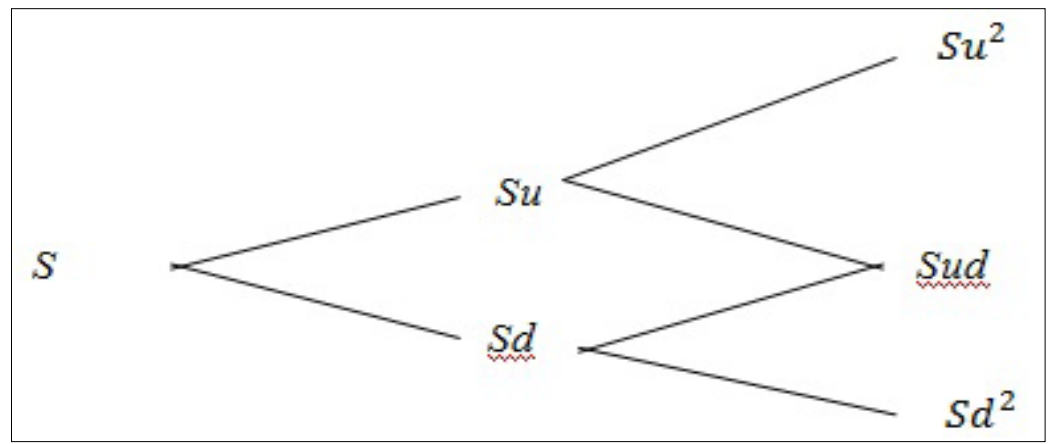

Figura 1. Modelo binomial

Fonte: Elaborado pelos autores

O deslocamento superior é determinado pelo preço atual da opção multiplicado pelo índice $u$ (equação 2), enquanto que no deslocamento inferior o preço atual do ativo subjacente é multiplicado por $d$, conforme a equação 3 . 
$u=e^{\sigma \sqrt{T}} d=\frac{1}{u}$

Em que, o ' $e$ ' é logaritmo de Neper $\cong 2,71828$, e ' $\sigma$ ' o desvio-padrão do evento que traz incerteza ao projeto.

Na segunda parte da árvore binomial as colunas são calculadas pelas abordagens ajustadas e neutras em relação ao risco, pelos índices $p$ e $q$ (COPELAND; ANTIKAROV, 2001; LIN e WESSEH JR, 2013).

$$
p=\frac{\left[\left(1+R_{f r e s}\right)-d\right]}{(u-d)} \text { e } q=1-p
$$

Em que, o $R_{\text {free }}=$ Ativo livre de risco.

As identidades de todas as variáveis que exigem cálculo neste estudo são apresentadas no Quadro 1 no Apêndice do artigo.

\section{APRESENTAÇÃO DOS RESULTADOS}

\subsection{PROSPECÇÃO DO FLUXO DE CAIXA}

A base do processo de valoração pelo FCD e posteriormente TOR decorre da prospecção do fluxo de caixa da termelétrica no futuro e, para tanto, se faz necessário conhecer o empreendimento e o seu atual desempenho financeiro.

\subsubsection{A planta termelétrica}

A usina termelétrica integra um grupo sucroenergético que possui mais de 50 anos de experiência neste setor e sua atuação é concentrada no Estado de São Paulo. A termelétrica alvo desta análise foi adquirida pelo grupo em 2008 pelo valor de R\$ 32 milhões (atualizado para janeiro/2014), como forma de diversificação do 
portfólio do grupo.

A venda de energia começou a ocorrer em 2011, pois entre 2008 e 2010 a termelétrica passou por adaptações nas suas instalações e os investimentos continuaram até 2013 quando a geração de energia alcançou a capacidade máxima. Na Tabela 1 são apresentados os fluxos de caixa da empresa para os credores (terceiros e próprio) para o período 2011 a 2013.

Tabela 1. Fluxo de caixa da termelétrica (R\$ em milhares)

\begin{tabular}{l|c|c|c}
\hline & $\mathbf{2 0 1 3}$ & $\mathbf{2 0 1 2}$ & $\mathbf{2 0 1 1}$ \\
\hline (+) Receita & 20.200 & 18.669 & 17.384 \\
\hline (-) Custos & 15.422 & 21.325 & 17.654 \\
\hline (=) Ebtida & 5.435 & -2.656 & -270 \\
\hline (-) Depreciação & 657 & 0 & 0 \\
\hline (-) Tributos & 762 & 614 & 559 \\
\hline (=) Fluxo de Caixa Operacional (FCO) & 4.673 & -3.270 & -829 \\
\hline (-) Investimento no Capital de Giro & -10.092 & -8.715 & 4.392 \\
\hline (-) Investimento em Imobilizado & -4.248 & 248 & 15.239 \\
\hline (=) Fluxo de Caixa Livre (FCL) & 19.013 & 5.197 & -20.460 \\
\hline
\end{tabular}

Fonte: Elaborada pelos autores.

Houve crescimento da receita da termelétrica desde o início da operação (2011), porém, há elevada dispersão nos custos e nos investimentos (capital de giro e imobilizado). Essa situação reflete o período em que a empresa não operava com plena capacidade e demandava investimentos na planta para garantir a eficiência esperada no projeto de engenharia.

Importa assinalar que, quando a termelétrica foi comprada, havia compromissos de entrega de energia já assumidos com clientes institucionais a um determinado preço fixo; no entanto, nos anos de 2011 e 2012 a termelétrica não conseguiu gerar a energia necessária para cumprir os contratos, com efeito, a empresa precisou comprar a diferença de energia no mercado spot. Esta operação gerou spread negativo, o que justifica os elevados custos nos anos de 2011 e 2012.

Salienta-se que a projeção do fluxo de caixa respeitará o horizonte temporal 
de dez anos e na sequência, utiliza-se o valor da empresa em perpetuidade.

\subsubsection{Projeção da receita}

A receita da termelétrica refere-se à venda de energia elétrica para o sistema em dois mercados (contrato de longo prazo e spot). Não foi possível desvelar junto aos entrevistados os percentuais de carga de cada mercado e o preço praticado.

Sendo assim, tomou-se a série histórica dos preços contratados em todos os leilões de energia para o segmento de biomassa do Ministério de Minas e Energia. A Tabela 2 traz os preços médios por MWh (aritmética simples) para cada ano e o desenvolvimento de três cenários (Mais provável, Pessimista e Otimista).

Tabela 2. Cálculo da taxa de crescimento nos três cenários

\begin{tabular}{l|c|c|c|c|c|c|c}
\hline Ano & $\mathbf{2 0 0 5}$ & $\mathbf{2 0 0 6}$ & $\mathbf{2 0 0 8}$ & $\mathbf{2 0 0 9}$ & $\mathbf{2 0 1 1}$ & $\mathbf{2 0 1 3}$ & Período \\
\hline $\begin{array}{l}\text { Média do Preço de Venda } \\
\text { da Energia Elétrica }\end{array}$ & 127,24 & 135,79 & 145,00 & 144,60 & 101,26 & 192,90 & \\
\hline Variação dos Preços & & $6,72 \%$ & $6,79 \%$ & $-0,28 \%$ & $-29,98 \%$ & $90,51 \%$ & $14,75 \%$ \\
\hline Crescimento & & & & & & & $51,61 \%$ \\
\hline $\begin{array}{l}\text { Desvio Padrão das Var- } \\
\text { iaçóes de Preços }\end{array}$ & & & & & & & $44,98 \%$ \\
\hline $\begin{array}{l}\text { Taxa de Crescimen- } \\
\text { to Cenário 1 (Mais } \\
\text { provável) }\end{array}$ & & & & & & & $5,34 \%$ \\
\hline $\begin{array}{l}\text { Taxa de Crescimento } \\
\text { Cenário 2 (Pessimista) }\end{array}$ & & & & & & & $0,81 \%$ \\
\hline $\begin{array}{l}\text { Taxa de Crescimento } \\
\text { Cenário 3 (Otimista) }\end{array}$ & & & & & & & $8,82 \%$ \\
\hline
\end{tabular}

Fonte: Elaborada pelos autores.

O crescimento de 51,61\% refere-se ao período da série histórica (20052013) o que entrega um crescimento anual equivalente a 5,34\% a.a., sendo esta a taxa de crescimento para o cenário 1 , denominado "mais provável".

Os dois cenários complementares foram tomados a partir do crescimento 
do período (51,61\%) e do desvio-padrão das variações de preços (44,98\%), assim, o valor do cenário 2 (pessimista) foi alcançado com a subtração da taxa de crescimento com o desvio-padrão, resultando no valor de $0,81 \%$ a.a. (6,63\% no período). No cenário 3 (otimista) somou-se o crescimento com o desvio-padrão do período e encontrou-se o valor de $8,82 \%$ a.a.

\subsubsection{Projeção dos custos e despesas}

O principal insumo da termelétrica é o bagaço da cana-de-açúcar fornecido pelo excedente não utilizado pelas plantas sucroalcooleiras do grupo. Considera-se, também, a possibilidade de aquisição do bagaço de outras usinas da região.

Os custos apurados no período 2010 a 2012 não refletem as condições operacionais normais da empresa. A perspectiva da gestão financeira da empresa é que os custos e as despesas operacionais desembolsáveis sejam inicialmente de $73 \%$ da receita o que entregaria uma Margem EBTIDA (Earn Before Taxes, Interest, Depreciation and Amortization) de $26,91 \%$.

Diante da expectativa da empresa de uma Margem EBITDA em 26,91\%, mensurou-se este indicador junto ao setor (CPFL Renovável, Desenvix, Elektro e Tractebel). Identificou-se a média de 46,38\% de Margem EBTIDA entre as empresas utilizadas como parâmetro, o que retrata a oportunidade desta termelétrica em aumentar a eficiência dos seus processos administrativos e operacionais.

\subsubsection{Depreciação e investimento}

Em razão dos registros contábeis incipientes, considerou-se a taxa de depreciação do setor que já apresenta maturidade na gestão de termelétricas. A taxa média de depreciação dos últimos três anos (2011-2013) para o setor foi de 6,19\% a.a.

A direção da empresa informou que o crescimento líquido do imobilizado da termelétrica será de 7,76\%, o que gera um indicador CAPEX/Depreciação de $107,76 \%$. Esse valor é inferior à média do setor aferida em 141\%. Utilizou-se o valor informado pela empresa, pois está associado ao seu plano de investimentos.

A Necessidade de Capital de Giro (NCG) da empresa foi estimada a partir do 
dimensionamento dos recursos correntes do modelo dinâmico do capital de giro, conforme a equação (06) (MATIAS, 2007).

$$
N C G=C F_{\text {dias }} \times \text { Receita }_{\text {dias }}
$$

Os resultados contábeis da empresa não permitem a determinação do Ciclo Financeiro $(\mathrm{CF})$ por meio dos prazos médios, contudo, foi apurado junto à controladoria que o CF ocorre em aproximadamente dez dias. Este valor é superior às empresas utilizadas como benchmarks que conseguem um nível de atividades com CF negativo em 12 dias. Entende-se que é possível uma nova reavaliação da empresa sobre o ciclo de atividades com o objetivo de redução da NCG. Para efeitos de valoração, utilizou-se o atual CF da empresa.

A Tabela 3 apresenta os valores do investimento em imobilizado, capital de giro e o valor da depreciação, considerando os três cenários previstos.

Tabela 3. Imobilizado, Capital de Giro e Depreciação (2014- 2023) (R\$ em milhares)

\begin{tabular}{l|c|c|c|c|c|c|c|c|c|c|c}
\hline & 2014 & 2015 & 2016 & 2017 & 2018 & 2019 & 2020 & 2021 & 2022 & 2023 \\
\hline & \multicolumn{10}{c}{ Cenário 1 (mais provável) } \\
\hline Imobilizado & 4.919 & 5.299 & 5.709 & 6.150 & 6.625 & 7.137 & 7.689 & 8.283 & 8.923 & 9.612 \\
\hline Capital de gGiro & 30 & 32 & 34 & 35 & 37 & 39 & 41 & 44 & 46 & 48 \\
\hline Depreciação & 4.245 & 4.573 & 4.926 & 5.307 & 5.717 & 6.159 & 6.635 & 7.147 & 7.700 & 8.295 \\
\hline & \multicolumn{10}{|c}{ Cenário 2 (otimista) } \\
\hline Imobilizado & 4.969 & 5.354 & 5.768 & 6.215 & 6.696 & 7.214 & 7.772 & 8.374 & 9.022 & 9.720 \\
\hline Capital de giro & 50 & 55 & 59 & 65 & 70 & 77 & 83 & 91 & 99 & 107 \\
\hline Depreciação & 4.245 & 4.573 & 4.926 & 5.307 & 5.717 & 6.159 & 6.635 & 7.147 & 7.700 & 8.295 \\
\hline & & \multicolumn{10}{|c|}{ Cenário 3 (pessimista) } \\
\hline Imobilizado & 4.919 & 5.299 & 5.709 & 6.150 & 6.625 & 7.137 & 7.689 & 8.283 & 8.923 & 9.612 \\
\hline Capital de gGiro & 5 & 5 & 5 & 5 & 5 & 5 & 5 & 5 & 5 & 5 \\
\hline Depreciação & 4.245 & 4.573 & 4.926 & 5.307 & 5.717 & 6.159 & 6.635 & 7.147 & 7.700 & 8.295 \\
\hline
\end{tabular}

Fonte: Elaborada pelos autores

\subsubsection{Estrutura de financiamento e custo do capital}


O Gráfico 1 apresenta a composição das fontes de financiamento dos investimentos da termelétrica, bem como o custo real da dívida no eixo secundário.

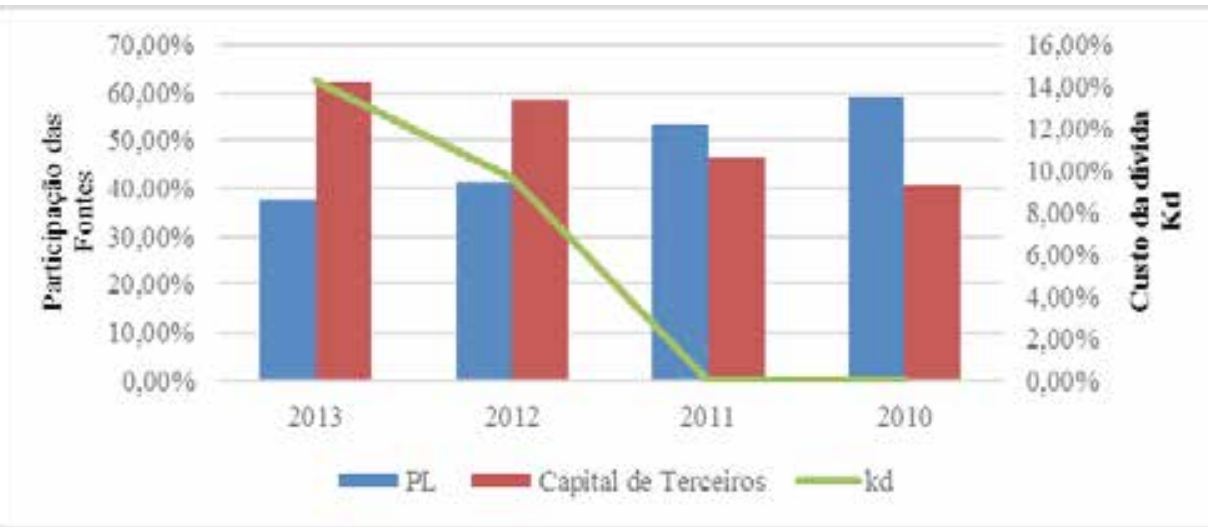

Gráfico 1. Estrutura de financiamento da empresa e custo da dívida Fonte: elaborado pelos autores

Verifica-se a inversão das fontes de financiamento em 2012 quando o capital de terceiros passa a representar o maior percentual (62\%) na estrutura de capital dos investimentos. Este crescimento ocorreu para financiar o spread negativo na venda de energia para cumprimento de obrigações contratuais no período de início da geração de energia (2011 e 2012).

A empresa não divulga a taxa de retorno requerida pelos acionistas, por isso, utilizou-se o beta médio das empresas CPFL Renovável e Tractebel considerando variações diárias entre 2013-2011. O valor médio dos betas foi de 0,505. A taxa livre de risco para o período analisado foi de $10,9 \%$ a.a. (Selic do período) e o prêmio de mercado foi o histórico do país em $6 \%$ a.a.

$\mathrm{O}$ retorno requerido para o capital próprio (Ke) foi calculado pelo (CAPM):

$$
K e=10,9+0,505 \times 6=13,93 \%
$$

Importante salientar que essa taxa de retorno é anual, sendo necessário deflacioná-la (ASSAF NETO, 2010). Como a meta de longo prazo para a inflação oficial do Brasil é 4,5\% (BCB, 2014), o retorno exigido deverá ser de 9,02\% a.a.

$\mathrm{O}$ custo da dívida $(\mathrm{Kd})$ foi determinado considerando o fator de dedutibili- 
dade do Imposto de Renda dessa despesa financeira. A alíquota utilizada foi de $34 \%$. A despesa financeira real para 2013 foi de $9,41 \%$, frente a despesa financeira nominal de $14,61 \%$. Todavia, a empresa estipulou a taxa real em $8,48 \%$, em função da atual substituição de contratos por outros com maiores garantias.

Para o cálculo do Weighted Average Cost of Capital (WACC) considerou-se a Estrutura de Capital (EC) atual da empresa que financia seus investimentos como segue:

$$
W A C C=\left[9,02 \times \frac{29.347}{76.714}\right]+\left[8,48 \times \frac{47.367}{76.714}\right]=8,69 \%
$$

No entanto, a estrutura de financiamento atual não será suportada no longo prazo, em razão da necessidade de liquidar provisões ainda relativas ao spread negativo dos contratos de fornecimento de energia, com efeito, espera-se aumento do passivo oneroso. A Tabela 4 traz a estrutura financeira projetada para a empresa.

Tabela 4. Evolução da estrutura de financiamento e custo da dívida (R\$ em milhares)

(continua)

\begin{tabular}{|c|c|c|c|c|c|c|c|c|c|c|}
\hline \multirow{2}{*}{$\begin{array}{l}\text { Elementos na } \\
\text { Estrutura do } \\
\text { Financiamento }\end{array}$} & \multicolumn{10}{|c|}{ Provável } \\
\hline & 2014 & 2015 & 2016 & 2017 & 2018 & 2019 & 2020 & 2021 & 2022 & 2023 \\
\hline $\begin{array}{l}\text { Crescimento do } \\
\text { investimento }\end{array}$ & 705 & 758 & 816 & 879 & 946 & 1.018 & 1.095 & 1.179 & 1.269 & 1.366 \\
\hline $\begin{array}{l}\text { Estrutura de financi- } \\
\text { amento }\end{array}$ & 23.599 & 47.367 & 47.367 & 47.367 & 47.367 & 47.367 & 47.367 & 47.367 & 47.367 & 47.367 \\
\hline $\begin{array}{l}\text { Necessidade de } \\
\text { financiamento }\end{array}$ & 24.304 & 48.125 & 48.183 & 48.246 & 48.313 & 48.385 & 48.462 & 48.546 & 48.636 & 48.733 \\
\hline $\begin{array}{l}\text { Custo da dívida } \\
\text { médio (Kd) }\end{array}$ & $8,48 \%$ & $8,48 \%$ & $8,48 \%$ & $8,48 \%$ & $8,48 \%$ & $8,48 \%$ & $8,48 \%$ & $8,48 \%$ & $8,48 \%$ & $8,48 \%$ \\
\hline Despesas financeiras & 2.061 & 4.081 & 4.086 & 4.091 & 4.097 & 4.103 & 4.109 & 4.116 & 4.124 & 4.132 \\
\hline
\end{tabular}


(conclusão)

\begin{tabular}{l|c|c|c|c|c|c|c|c|c|c}
\hline $\begin{array}{l}\text { Elementos na } \\
\text { estrutura do finan- } \\
\text { ciamento }\end{array}$ & $\mathbf{2 0 1 4}$ & $\mathbf{2 0 1 5}$ & $\mathbf{2 0 1 6}$ & $\mathbf{2 0 1 7}$ & $\mathbf{2 0 1 8}$ & $\mathbf{2 0 1 9}$ & $\mathbf{2 0 2 0}$ & $\mathbf{2 0 2 1}$ & $\mathbf{2 0 2 2}$ & $\mathbf{2 0 2 3}$ \\
\cline { 2 - 11 } & 679 & 731 & 787 & 848 & 913 & 983 & 1.059 & 1.140 & 1.228 & 1.323 \\
\hline $\begin{array}{l}\text { Crescimento do } \\
\text { investimento }\end{array}$ & 23.599 & 47.367 & 47.367 & 48.189 & 49.840 & 49.840 & 49.840 & 49.840 & 49.840 & 49.840 \\
\hline $\begin{array}{l}\text { Estrutura de financi- } \\
\text { amento }\end{array}$ & 24.278 & 48.098 & 48.154 & 49.037 & 50.753 & 50.823 & 50.899 & 50.980 & 51.068 & 51.163 \\
\hline $\begin{array}{l}\text { Necessidade de } \\
\text { financiamento }\end{array}$ & $8,48 \%$ & $8,48 \%$ & $8,48 \%$ & $8,48 \%$ & $8,48 \%$ & $8,48 \%$ & $8,48 \%$ & $8,48 \%$ & $8,48 \%$ & $8,48 \%$ \\
\hline $\begin{array}{l}\text { Custo da dívida } \\
\text { médio (Kd) }\end{array}$ & 2.059 & 4.078 & 4.083 & 4.158 & 4.303 & 4.309 & 4.316 & 4.323 & 4.330 & 4.338 \\
\hline \begin{tabular}{l} 
Despesas financeiras \\
\hline
\end{tabular}
\end{tabular}

\begin{tabular}{l|c|c|c|c|c|c|c|c|c|c}
\hline $\begin{array}{l}\text { Elementos na } \\
\text { estrutura do finan- } \\
\text { ciamento }\end{array}$ & $\mathbf{2 0 1 4}$ & $\mathbf{2 0 1 5}$ & $\mathbf{2 0 1 6}$ & $\mathbf{2 0 1 7}$ & $\mathbf{2 0 1 8}$ & $\mathbf{2 0 1 9}$ & $\mathbf{2 0 2 0}$ & $\mathbf{2 0 2 1}$ & $\mathbf{2 0 2 2}$ & $\mathbf{2 0 2 3}$ \\
\cline { 2 - 10 } & 724 & 781 & 842 & 908 & 979 & 1.055 & 1.137 & 1.226 & 1.322 & 1.425 \\
\hline $\begin{array}{l}\text { Crescimento do } \\
\text { investimento }\end{array}$ & 23.599 & 47.367 & 47.367 & 47.368 & 47.369 & 47.369 & 47.369 & 47.369 & 47.369 & 47.369 \\
\hline $\begin{array}{l}\text { Estrutura de financi- } \\
\text { amento }\end{array}$ & 24.323 & 48.148 & 48.209 & 48.276 & 48.347 & 48.423 & 48.506 & 48.595 & 48.690 & 48.794 \\
\hline $\begin{array}{l}\text { Necessidade de } \\
\text { financiamento }\end{array}$ & $8,48 \%$ & $8,48 \%$ & $8,48 \%$ & $8,48 \%$ & $8,48 \%$ & $8,48 \%$ & $8,48 \%$ & $8,48 \%$ & $8,48 \%$ & $8,48 \%$ \\
\hline $\begin{array}{l}\text { Custo da dívida } \\
\text { médio (Kd) }\end{array}$ & 2.062 & 4.083 & 4.088 & 4.093 & 4.099 & 4.106 & 4.113 & 4.120 & 4.129 & 4.137 \\
\hline \begin{tabular}{l} 
Despesas financeiras \\
\hline
\end{tabular}
\end{tabular}

Fonte: Elaborada pelos autores

As variações nos cenários devem-se, fundamentalmente, às variações no capital de giro que difere em função das expectativas de receita previstas para cada horizonte. Manteve-se o custo da dívida uniforme ao longo do tempo, em função da meta estipulada pela empresa, assim como a manutenção do custo do patrimônio líquido (Ke), em que pese a limitação dessa decisão.

$\mathrm{Na}$ Tabela 5 apresentam-se somente os indicadores financeiros padronizados referentes à rentabilidade, estrutura de capital e a geração de caixa para os anos 2011, 2012 e 2013. 
Tabela 5. Indicadores financeiros da empresa

\begin{tabular}{|c|c|c|c|c|}
\hline Categorias & Indicadores & 2013 & 2012 & 2011 \\
\hline \multirow{2}{*}{ Rentabilidade } & ROI & $12,76 \%$ & $-7,07 \%$ & $-1,57 \%$ \\
\hline & ROE & $12,67 \%$ & $-11,10 \%$ & $-2,13 \%$ \\
\hline \multirow{3}{*}{ Geração de caixa } & Margem FCO & $75,24 \%$ & $29,54 \%$ & $-33,96 \%$ \\
\hline & ROS & $19,06 \%$ & $-21,56 \%$ & $-4,77 \%$ \\
\hline & Giro do ativo & 0,25 & 0,21 & 0,24 \\
\hline \multirow{5}{*}{ Solvência } & Estrutura de financiamento & $62,27 \%$ & $58,56 \%$ & $46,38 \%$ \\
\hline & $\mathrm{Kd}$ & $14,26 \%$ & $9,62 \%$ & $0,00 \%$ \\
\hline & Cobertura de dívidas & 0,3 & 0,11 & $-0,17$ \\
\hline & LC & 0,31 & 0,61 & 0,54 \\
\hline & Equilíbrio financeiro & $-0,87$ & $-0,54$ & $-0,25$ \\
\hline
\end{tabular}

Fonte: Elaborada pelos autores.

Nos dois primeiros anos, conforme Tabela 5, a empresa apresentou rentabilidade negativa, sendo que o ROE sempre foi inferior ao retorno dos investimentos, o que sinaliza para um financiamento inadequado dos ativos (ASSAF NETO, 2010). Em 2013, a empresa apresentou o seu melhor resultado em nível de rentabilidade, em função da melhoria na margem do fluxo de caixa operacional, giro do ativo e do retorno sobre as vendas. Não obstante, o ROE continua inferior ao investimento, fruto do custo da dívida (kd) ser mais alto que o ROI.

Os índices de rentabilidade e geração de caixa melhoraram no período, pois reportavam um resultado negativo em 2011 e, em 2013, os valores para todos os indicadores foram positivos, com destaque para a Margem FCO que encerrou 2013 com $75,24 \%$ frente $-33,95 \%$ em 2011 (Tabela 5).

Por outro lado, os indicadores de solvência elencados na Tabela 5 mostram que a empresa tem financiado seu capital de giro de forma inadequada, pois o indicador de equilíbrio financeiro é negativo em todo o período; ressalta-se que o numerador do EF é o Capital Circulante Líquido (Apêndice 1) e o divisor é a receita, portanto, a redução deste indicador na dimensão negativa no curso do tempo reflete o crescimento da receita com o aumento do capital circulante líquido negativo. Este evento é ratificado pelo comportamento da LC que reportou valores inferiores a 1 , também em todos os anos.

A Tabela 5 mostra que a termelétrica possui capacidade de geração de caixa e rentabilidade com operação em plena capacidade, em vistas à Margem do FCO de 
$73 \%$ e o ROI superior ao WACC (12,76\% frente 8,69\%), porém a estrutura de capital mostra-se inadequada para o financiamento do capital de giro (ASSAF NETO, 2010).

Desta forma, as obrigações contraídas pela empresa junto aos terceiros é um dos principais "gargalos" na viabilidade financeira do investimento. Como se trata de uma empresa intensiva em imobilizado verificou-se como flexibilidade gerencial a oportunidade, no futuro, de venda da termelétrica pelo valor de face da dívida, na hipótese do seu valor intrínseco ser inferior ao valor das obrigações contraídas.

\subsection{FLUXO DE CAIXA DESCONTADO}

A Tabela 6 traz os fluxos de caixa projetados para os dez anos no cenário provável. Foi utilizada uma taxa de crescimento de 5,34\%, conforme apresentado na Tabela 2. A taxa de crescimento da receita também foi utilizada para o cálculo da perpetuidade.

Tabela 6. Fluxo de caixa incremental termelétrica cenário 1 (R\$ em milhares)

\begin{tabular}{|c|c|c|c|c|c|c|c|c|}
\hline & 2014 & 2015 & 2016 & 2017 & $(\ldots)$ & 2022 & 2023 & Perpetuidade \\
\hline (+) Receita & 21.279 & 22.415 & 23.612 & 24.872 & & 32.260 & 33.983 & \\
\hline$(-)$ Custos + despesas & 15.553 & 16.384 & 17.259 & 13.337 & & 17.298 & 18.222 & \\
\hline (=) EBTIDA & 5.725 & 6.031 & 6.353 & 11.536 & & 14.962 & 15.761 & \\
\hline (-) Depreciação & 4.245 & 4.573 & 4.926 & 5.307 & & 7.700 & 8.295 & \\
\hline$(=)$ LAIR & 1.480 & 1.458 & 1.427 & 6.229 & & 7.263 & 7.466 & \\
\hline (-) IR/CSLL & 473 & 466 & 455 & 2.088 & & 2.439 & 2.509 & \\
\hline (+) Depreciação & 4.245 & 4.573 & 4.926 & 5.307 & & 7.700 & 8.295 & \\
\hline$(=) \mathrm{FCO}$ & 5.252 & 5.565 & 5.898 & 9.448 & & 12.523 & 13.253 & \\
\hline$(-) \mathrm{CDG}$ & 30 & 32 & 34 & 35 & & 46 & 48 & \\
\hline (-) Imobilizado & 4.919 & 5.299 & 5.709 & 6.150 & & 8.923 & 9.612 & \\
\hline$(=)$ FCL & 302 & 234 & 155 & 3.263 & & 3.554 & 3.592 & 69.236 \\
\hline$(=)$ FCD & 278 & 198 & 121 & 2.338 & & 1.679 & 1.561 & 27.692 \\
\hline VP Empresa & 41.854 & Dívida & 48.432 & & & & & \\
\hline VP Patrimônio líquido & -6.578 & TIR & $1,94 \%$ & & & & & \\
\hline
\end{tabular}

Fonte: Elaborada pelos autores. 
Observa-se na Tabela 6 que a TIR do empreendimento (1,94\%) é inferior ao custo médio ponderado de capital da empresa (8,69\%), o que gera um VP do patrimônio líquido (PL) negativo (R \$ 6,578 milhões), pois o atual valor da dívida (R\$ 48,4 milhões) é maior que o VP da termelétrica investimento no cenário provável ( $\mathrm{R} \$ 41,8$ milhões).

Assim como o desenvolvimento do FCL do cenário 1 (mais provável), desenvolveram-se os cenários 2 (otimista) e 3 (pessimista). As taxas de crescimento foram de $8,82 \%$ (otimista) e $0,81 \%$ (pessimista). Estes valores foram encontrados a partir da volatilidade do preço da energia, conforme exposto na Tabela 2.

A Tabela 7 traz os valores consolidados da planta em função da sua capacidade de geração de fluxo de caixa livre para os três cenários e o resultado líquido para os acionistas do grupo.

Tabela 7. Valores presentes dos FCI dos três cenários (R\$ em milhares)

\begin{tabular}{c|c|c|c}
\hline Cenários & Valor presente $\mathbf{( V P )}$ & Dívida & VP do PL \\
\hline Provável & 41.854 & 48.432 & -6.578 \\
\hline Otimista & 81.480 & 48.432 & 33.048 \\
\hline Pessimista & 4.061 & 48.432 & -44.371 \\
\hline Média & $\mathbf{4 2 . 4 6 5}$ & $\mathbf{4 8 . 4 3 2}$ & $\mathbf{- 5 . 9 6 7}$ \\
\hline
\end{tabular}

Fonte: Elaborada pelos autores.

Verifica-se que a média dos cenários é negativa em $\mathrm{R} \$$ 5,967 milhões, o que sugere que a termelétrica seja negociada no momento atual pelo valor de face da dívida; todavia, no cenário otimista o VP do PL pode alcançar o valor de R\$33,048 milhões, com a tendência otimista do preço da energia em $8,82 \%$ a.a. (Tabela 2 ).

Neste sentido, surge a necessidade de melhor avaliação da termelétrica, com vistas a capturar a flexibilidade de aguardar que novas informações ocorram e que eventualmente possam tornar o investimento uma fonte de criação de riqueza.

\subsection{OPÇÕES REAIS}

Utilizaram-se as opções reais com o modelo binominal tendo como base o desvio-padrão do preço da energia em 41,41\% (Tabela 2). Sendo assim, os índices 
$u(u p)$ e $d$ (down), no caso da empresa, foram 1,5130 e 0,6609 (Equações 2 e 3), respectivamente. A Figura 2 apresenta a distribuição dos valores da empresa ao longo de dez anos, sendo o valor inicial, o valor presente médio do valor da empresa determinado na Tabela 7.

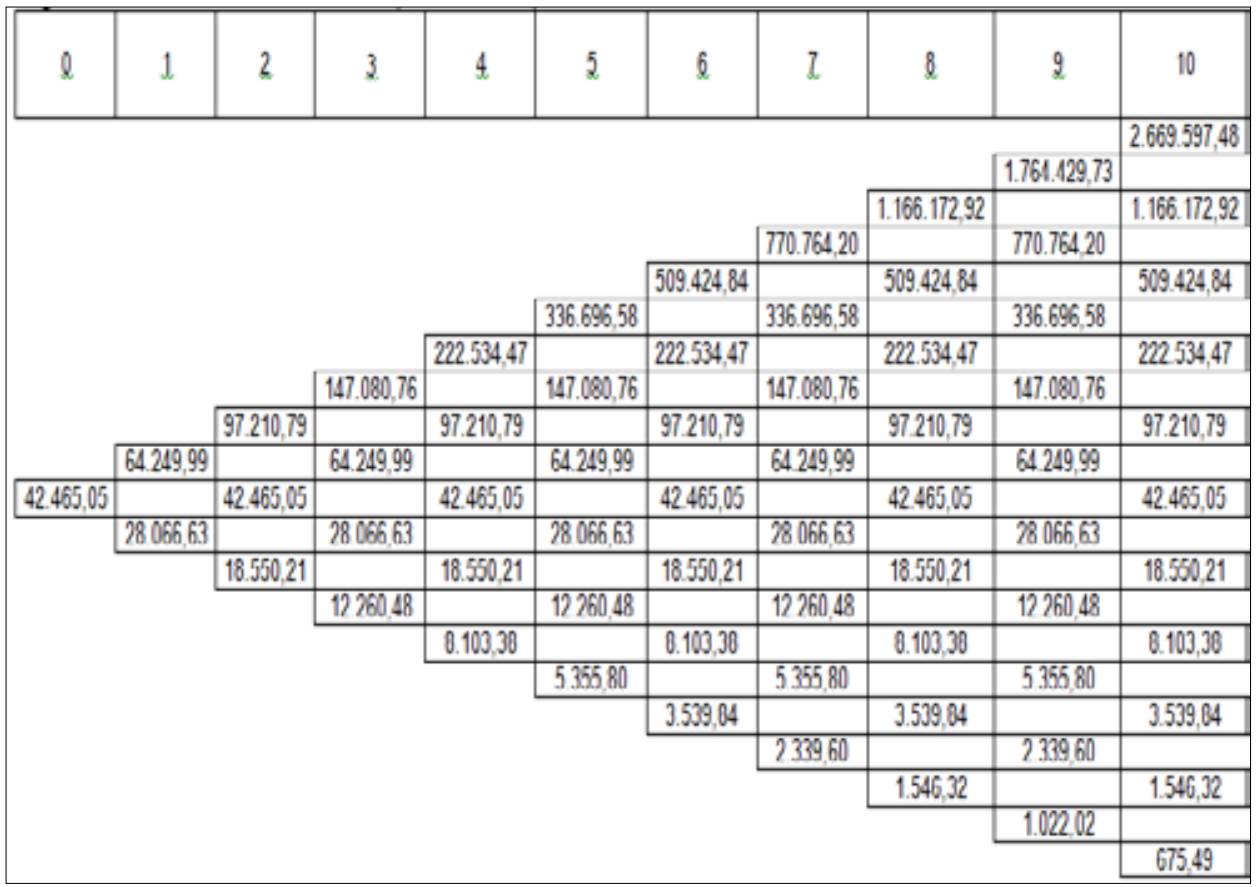

Figura 2. Árvore de Decisão Termelétrica (R\$ em milhares Fonte: Elaborado pelos autores

$\mathrm{Na}$ Figura 2, pode-se observar o deslocamento do VP médio inicial (R\$ 42,465 milhões) da termelétrica segundo os movimentos de subida $(u)$ e descida $(d)$ em um processo multiplicativo, conforme a Figura 1.

A Figura 3 apresenta o valor para os acionistas, considerando a flexibilidade de venda da planta a longo do período, pelo valor de face da dívida. Para calcular o valor da opção foi considerada a projeção do valor da dívida no tempo. Para efeitos de simplificação, admitiu-se que a empresa pagaria as despesas financeiras com novo 
endividamento, assim a dívida alcançaria o valor no ano 10 de $\mathrm{R} \$ 111,436$ milhões.

Desta forma, se o valor da empresa for inferior à dívida, o acionista não tem direito algum sobre o empreendimento, de modo que poderia "transferi-lo" para os credores.

\begin{tabular}{|c|c|c|c|c|c|c|c|c|c|c|}
\hline Valor de saida & $52,640,74$ & $57.215,22$ & $62,187,22$ & $67.591,29$ & $73.464,98$ & $79.849,08$ & \multirow{2}{*}{$\begin{array}{c}86.787,97 \\
\end{array}$} & $94,329,84$ & \multirow{2}{*}{$\begin{array}{l}102.527,11 \\
2 \\
\end{array}$} & \multirow{2}{*}{$\begin{array}{l}111.436,71 \\
10\end{array}$} \\
\hline \multirow{11}{*}{$l$} & 1 & 2 & 3 & 4 & 5 & 6 & & 8 & & \\
\hline & & & & & & & & \multirow{2}{*}{\multicolumn{2}{|c|}{$1.663 .945,77$}} & $2.558 .160,77$ \\
\hline & & & & & & & & & & \\
\hline & & & & & & & & \multicolumn{2}{|l|}{$1.075 .565,20$} & $1.054 .736,21$ \\
\hline & & & & & & & $689.062,02$ & & $670.280,24$ & \\
\hline & & & & & & 436.228 .25 & & $418.817,12$ & & $397.988,13$ \\
\hline & & & & & $272.377,91$ & & 256.106 .20 & & $236.212,62$ & \\
\hline & & & & 167.606 .5 & & $153.275,86$ & & $134.527,17$ & & $111.097,76$ \\
\hline & & & $101.645,51$ & & $89.940,36$ & & $74.468,04$ & & $52.679,03$ & \\
\hline & & $60.785,82$ & & $51.858,46$ & & $40.374,27$ & & $24.978,72$ & & l \\
\hline & $35.874,74$ & & $29.444,26$ & & $21.545,33$ & & $11,844,12$ & & l & \\
\hline $20.914,76$ & & $16.494,26$ & & $11.354,66$ & & $5.616,10$ & & & & l \\
\hline & $9.131,44$ & & $5.923,88$ & & $2.662,98$ & & l & & l & \\
\hline & & $3.064,90$ & & $1.262,70$ & & l & & & & l \\
\hline & & & 598,73 & & l & & l & & l & \\
\hline & & & & l & & l & & & & l \\
\hline & & & & & l & & l & & l & \\
\hline & & & & & & l & & & & l \\
\hline & & & & & & & l & & l & \\
\hline & & & & & & & & & & $l$ \\
\hline & & & & & & & & & & \\
\hline
\end{tabular}

Figura 3. Árvore de Decisão (Opção de vendas) (R\$ em milhares)

Fonte: Elaborada pelos autores

A Figura 3 apresenta a inclusão da flexibilidade em 'abandonar' o investimento pelo valor de face da dívida. O processo para tomar essa decisão deve começar pela abordagem binominal de "trás para frente" (COPELAND; ANTIKAROV, 2001).

Assim, tomaram-se os valores presentes médios da termelétrica na Figura 1 no ano 10 e destes valores foi descontado o montante da dívida atualizado para aquele ano. Por isso, o maior valor no ano 10 do patrimônio líquido é $\mathrm{R} \$ 2,558$ milhões (R\$ 2.669,497 milhões - 111,436 milhões). Nota-se na Figura 3 que no ano 
10 há sete possibilidades de valores "zerados". Nestas possibilidades de ocorrência a diferença entre o valor da empresa e o valor da dívida seria negativa, portanto, a decisão seria 'entregar' a termelétrica para os credores e limitar o prejuízo dos acionistas no total dos investimentos já realizados (sunk costs) (DAMODARAN, 2010).

Para calcular os valores do ano 9, foi necessário identificar o valor da dívida atualizado para aquele ano, como segue:

$$
\text { Valor de saída } a_{\text {ano } 9}=48.432,00 x\left(1+8,69 \%{ }^{9}\right)=R \$ 102.527,11
$$

Lembre-se que a taxa de 8,69\% refere-se ao WACC da termelétrica, calculado na seção 4.1.5 e cuja fórmula encontra-se no Apêndice 1 do artigo. Assim, no ano 9 usa-se como base a última coluna da Figura 3 e as probabilidades neutras a risco de subida $(p)$ e descida $(q)$, foram assim calculadas, conforme as Equações 04 e 05 :

$$
\begin{gathered}
p=\frac{[(1+10,9 \%)-0,6609]}{(1,5130-0,6609)}=0,5258 \\
q=1-0,5258=0,4742
\end{gathered}
$$

A partir dos valores do PL calculados no ano 10 e das probabilidades "p" e "q", os valores dos "nós" do ano 9 foram calculados como segue:

$$
\begin{gathered}
1^{\circ} \text { nó }_{\text {ano } 9}=\frac{[(2.558 .160,77 \times 0,5258)+(1.054 .736,21 \times 0,4742)]}{(1+10,9 \%)}=1.663 .945,77 \\
2^{\circ} \text { nó }_{\text {ano } 9}=\frac{[(1.054 .736,21 \times 0,5258)+(397.988,13 \times 0,4742)]}{(1+10,9 \%)}=670.280,24 \\
3^{\circ} \text { nó }_{\text {ano } 9}=\frac{[(397.988,13 \times 0,5258)+(111.097,76 \times 0,4742)]}{(1+10,9 \%)}=236.212,62 \\
4^{\circ} \text { nó }_{\text {ano } 9}=\frac{[(111.097,76 \times 0,5258)+(0 \times 0,4742)]}{(1+10,9 \%)}=52.679,03
\end{gathered}
$$

A taxa livre de risco utilizada foi de 10,9\% a.a., definida na seção 4.1.5.

Após o quarto "nó" do ano 9, que apresentou valor positivo de $\mathrm{R} \$ \mathbf{5 2 , 6 7 9}$ milhões, todos os valores são zerados, pois os valores futuros correspondentes no 
ano 10 seriam inferiores ao valor de face da dívida e, portanto, seria mais vantajoso para o grupo econômico a "entrega" da termelétrica aos credores.

Para os demais anos os cálculos são efetuados da mesma maneira, e os valores do PL com a opção de venda estão demonstrados na Figura 3. Verifica-se que no momento atual ("0"), o Valor Presente do PL da termelétrica é positivo em R\$ 20,9 milhões. Observa-se, também, que a termelétrica não deve exercer a opção de abandono até o terceiro ano e, a partir deste, deve-se considerar tal flexibilidade em função do valor presente da termelétrica.

A análise por meio das opções reais mostrou-se mais ajustada na valoração da termelétrica frente o Fluxo de Caixa Descontado que sinaliza para um VP do PL negativo em $\mathrm{R} \$ 5,967$ milhões, quando se analisa pelas opções reais o valor estimado do PL foi de R\$20,9 milhões. Essa diferença decorre da melhor estrutura de análise do investimento com a inclusão da flexibilidade da gestão em poder abandonar o investimento pelo valor de face da dívida como preço de exercício.

\section{CONSIDERAÇÕES FINAIS}

A valoração de um ativo é um processo complexo, pois envolve a estimativa futura de variáveis internas e externas ao investimento e, neste processo, as possibilidades de equívocos são elevadas (DAMODARAN, 2007). Apesar da abrangência das variáveis necessárias para valoração da termelétrica deste estudo, foi possível alcançar os objetivos iniciais que foram a valoração do investimento e a capacidade deste de criação de riqueza.

A termelétrica apresentou um valor de mercado de $\mathrm{R} \$ 69,346$ milhões, sendo $\mathrm{R} \$ 20,914$ milhões o valor do patrimônio líquido e $\mathrm{R} \$$ 48,432 milhões de dívidas.

O fluxo de caixa apresentado pela empresa nos primeiros anos de operação (2011 e 2012) reportou um desempenho nas dimensões de rentabilidade e geração de caixa insuficiente face ao custo de oportunidade da empresa.

O ano de 2013 apresentou melhor desempenho da empresa, porém a estrutura de financiamento é inadequada em razão da presença de passivos de curto prazo financiando ativos de longo prazo o que compromete a liquidez da termelétrica.

A inclusão da flexibilidade gerencial em abandonar a termelétrica pelo valor 
de face da dívida, reconhecendo que há incerteza nos preços futuros dos contratos de energia, foi melhor trabalhada na valoração por meio das opções reais que demonstrou que o atual valor presente do patrimônio líquido é positivo em $\mathrm{R} \$ 20,9$ milhões.

Diante disso, o grupo que comprou a termelétrica deve manter este investimento no seu portfólio e acompanhar a evolução do valor de mercado da empresa diante da volatilidade do preço da energia nos contratos futuros. Em adição, devese dedicar atenção à estrutura de financiamento da empresa e melhorar o nível de margem do FCO diante da média dos benchmarks de mercado com o objetivo de garantir a criação de riqueza para os acionistas.

A realização deste estudo de caso possibilitou além da aplicação da TOR na valoração de uma termelétrica de biomassa a sinalização do período e condições para tomada de decisão de abandono, exemplificando o uso desta metodologia em um setor de relevante importância para o país. Apesar da impossibilidade de replicar os resultados para outros contextos em razão da restrição do estudo de caso e as especificidades dessa termelétrica, espera-se que o detalhamento do processo de valoração contribua na discussão de outros processos precificação.

Nessa direção, sugere-se a valoração de: i) plantas sucroenergéticas com a opção de alteração do mix de produção (etanol e açúcar); ii) o valor da palha da cana como recurso para proteger o solo pós-colheita ou na geração de energia; iii) a constituição do portfólio de contratos de energia entre contratos de longo prazo e mercado spot; iv) aumentar a flexibilidade das usinas com processamento de milho.

\section{REFERÊNCIAS}

AGENCIA NACIONAL DE ENERGIA ELÉTRICA (ANEEL) Atlas de Energia Elétrica do Brasil. 3. ed. Brasília, DF: ANEEL, 2012.

ASSAF NETO, A. Finanças Corporativas e Valor. 5. ed. São Paulo: Atlas, 2010.

BANCO CENTRAL DO BRASIL (BCB). Relatório de Inflação Dezembro de 2014. Relatório de Inflação, Brasília, v. 16, n. 4, p. 1-103, 2014.

BASTIAN-PINTO, C. L.; BRANDÃO, L. E. T. Modelando Opções de Conversão com 
Movimento de Reversão à Média. Revista Brasileira de Finanças, Rio de Janeiro, v. 5, n. 2, p. 97-124, 2007.

BRASIL. Ministério de Minas e Energia. Leilóes de energia elétrica. Brasília, 2014. Disponível em:http://www.mme.gov.br/programas/leiloes_de_energia/menu/inicio. html. Acesso em: 11 set. 2014.

CESEÑA, E. A. M.; MUTALE, J. Application of na Advanced Real Options approach for Renewable Energy Generation Projects Planning. Revewable and Sustainable Energy Reviews, 15, p.2087-2094, 2011.

CESEÑA, E. A. M.; MUTALE, J.; RIVAS-DÁVALOS, F. Real Options Theory applied to Electricity Generation Projects: A Review. Revewable and Sustainable Energy Reviews, 19, p.573-581, 2013.

CHUNG, C. C.; LEE, S-H.; BEAMISH, P. W.; SOUTHAM, C.; NAM, D. DALE. Pitting Real Options Theory against risk Diversification Theory: International Diversification and Joint Ownership Control in economic crisis. Journal of World Business, 48, p. 122-136, 2013.

COPELAND, T.; ANTIKAROV, V. Opções Reais: Um novo Paradigma para Reinventar a Avaliação de Investimentos. Rio de Janeiro: Campus, 2001.

COX, J. C.; ROSS, S. A.; RUBINSTEIN, M. Option Pricing: a simplified approach. Journal of Financial Economics, Amsterdam, v. 7, n. 3, p. 229-264, 1979.

DAMODARAN, A. Avaliação de Investimentos: Ferramentas e Técnicas para a Determinação do Valor de Qualquer Ativo. Rio de Janeiro: Qualitymark, 2010.

FERNANDES, B.; CUNHA, J.; FERREIRA, P. The use of Real Options approach in Energy Sector Investments. Renewable and Sustainable Energy Reviews, 15, p.4491-4497, 2011.

FIGUEIRA, S. F.; BORGES, A. C. G.; SANTOS, D. F. L. Análise Comparativa da Evolução dos Índices de Concentração da Demanda por Combustíveis Automotivos no Brasil no Período de 2000 até 2011. Informações Econômicas, São Paulo, v. 43, n. 1, p. 59-72, 2013. 
GRAHAM, J. R.; HARVEY, C. R. The theory and practice of corporate finance: evidence from the field. Journal of Financial Economics, Amsterdam, v. 60, n. 2-3, p. 187-243, 2001.

GRULLON, G.; LYANDRES, E.; ZHDANOV, A. Real Options, Volatility, and Stock Returns. The Journal of Finance, LXVII, n.4, August, 2012.

KALLIO, M.; KUULA, M. OINONEN, S. Real Options Valuation of Forest Plantation Investment in Bazil. European Journal of Operational Research, 217, p. 428-438, 2012.

LIN, B.; WESSEH JR, P. K. Valuing Chinese feed-in Tariffs program for Solar Power Generation: A Real Options Analysis. Renewable and Sustainable Energy Reviews, 28, p. 474-482, 2013.

MATIAS, A. B. (ORG.). Finanças Corporativas de Curto Prazo: A Gestão do Valor do Capital de Giro. São Paulo: Atlas, 2007.

MILANESI, G. S. Valoración Probabilística versus Borrosa, OpcionesReales y el Modelo Binomial. Aplicación para Proyectos de Inversión em Condiciones de Ambigüedad. Estudios Gerenciales, 30, p.211-219, 2014.

MUSSHOFF, O. Growing short Rotation coppice on Agricultural land in Germany: A Real Options Approach. Biomass and Bioenergy, 41, p.73-85, 2012.

PINDYCK, R. S. Investments of Uncertain Costs. Journal of Financial Economics, Amsterdam, v. 34, n. 1. p. 53-76, 1993.

SANTOS, D. F. L.; REBELATO, M. G.; RODRIGUES, A. M. Análise da Viabilidade Econômica de uma Planta para Captura de $\mathrm{CO}_{2}$ na Indústria Alcooleira. Gestão \& Tecnologia, Pedro Leopoldo, v. 12, n. 2, p. 64-88, 2012.

SANTOS, D. F. L.; BASSO, L. F. C.; KIMURA, H; SOBREIRO, V. A. Eco-innovation in theBrazilian sugar-ethanolindustry: a case study. Brazilian Journal of Science and Technology, [S.1.], v. 2, n. 1, p. 1-15, 2015. 
SANTOS, E. M.; PAMPLONA, E. de O. Teoria das Opções Reais: Uma Atraente Opção do Processo de Análise de Investimentos. Revista de Administração da USP, São Paulo, v. 40, n. 3, p. 235-252, 2005.

SANTOS, L.; SOARES, I.; MENDES, C.; FERREIRA, P. Real Options versus Traditional Methods to assess Renewable Energy Projects. Renewable Energy, 68, p. 588-594, 2014.

SPETIC, W.; MARQUEZ, P.; KOZAK, R. Critical area sand entry points for sustainability - related strategies in the sugarcane - based ethanol industry of Brazil. Business Strategy and the Environment, West Sussex, v. 21, p. 370-386, 2012.

UNIÃO DA INDÚSTRIA DE CANA-DE-AÇÚCAR (UNICA). Setor sucroalcooleiro. São Paulo, 2012.Disponível em:http://www.unica.com.br. Acesso em: 27 de jul. 2014.

WANG, X.; CAI, Y.; DAI, C. Evaluating China's Biomass power Production Investment based on a Policy Benefit Real Options Model. Energy, 73, p.751-761, 2014.

YIN, R. K. Estudos de caso: planejamento e métodos. 3. ed. Porto Alegre: Bookman, 2005.

Recebido em: 24 de março de 2015 Aceito em: 26 de julbo de 2016 


\section{APÊNDICE 1}

Quadro 1. Discriminação das variáveis de cálculo utilizadas no estudo

\begin{tabular}{|c|c|c|}
\hline $\begin{array}{c}\text { Descrição da Variável e } \\
\text { Sigla }\end{array}$ & Referência & Fórmula \\
\hline $\begin{array}{l}\text { Valor Presente do Ativo } \\
\text { (Valor) }\end{array}$ & $\begin{array}{l}\text { (DAMODARAN, } \\
\text { 2010) }\end{array}$ & $\sum_{t=1}^{t=n} \frac{C F_{t}}{(1+r)^{t}}$ \\
\hline $\begin{array}{l}\text { Movimento de subida }(u p) \\
\text { do Modelo Binominal }(u)\end{array}$ & $\begin{array}{l}\text { (COX, ROSS e } \\
\text { RUBIENSTEIN, } \\
\text { 1979) }\end{array}$ & $e^{\sigma \sqrt{T}}$ \\
\hline $\begin{array}{l}\text { Movimento de desci- } \\
\text { da (down) do Modelo } \\
\text { Binominal }\end{array}$ & $\begin{array}{l}\text { (COX, ROSS e } \\
\text { RUBIENSTEIN, } \\
\text { 1979) }\end{array}$ & $d=\frac{1}{u}$ \\
\hline $\begin{array}{l}\text { Probabilidade Neutra a } \\
\text { Risco do Movimento de } \\
\text { subida }(p)\end{array}$ & $\begin{array}{l}\text { (COPELAND e } \\
\text { ANTIKAROV, } \\
\text { 2001) }\end{array}$ & $p=\frac{\left[\left(1+R_{f r e \theta}\right)-d\right]}{(u-d)}$ \\
\hline $\begin{array}{l}\text { Probabilidade Neutra a } \\
\text { Risco do Movimento de } \\
\text { subida }(p)\end{array}$ & $\begin{array}{l}\text { (COPELAND e } \\
\text { ANTIKAROV, } \\
\text { 2001) }\end{array}$ & $q=1-p$ \\
\hline $\begin{array}{l}\text { Necessidade de capital de } \\
\text { giro (NCG) }\end{array}$ & $\begin{array}{l}\text { (ASSAF NETO, } \\
2010)\end{array}$ & $N C G=C F_{\text {dias }} \times$ Receita $_{\text {dias }}$ \\
\hline $\begin{array}{l}\text { Retorno requerido pelo } \\
\text { capital próprio (Equity) } \\
(\mathrm{Ke})\end{array}$ & $\begin{array}{l}\text { (DAMODARAN, } \\
\text { 2010): }\end{array}$ & $K e_{i}=R_{\text {fres }}+\beta_{i}\left(R_{m}-R_{\text {fres }}\right)$ \\
\hline $\begin{array}{l}\text { Risco não Diversificável do } \\
\text { projeto }\left(\beta_{i}\right)\end{array}$ & $\begin{array}{l}\text { (DAMODARAN, } \\
2010)\end{array}$ & $\beta_{i}=\frac{\operatorname{COVAR_{i,m}}}{\sigma_{m}^{2}}$ \\
\hline $\begin{array}{l}\text { Custo da dívida médio } \\
(K d)\end{array}$ & $\begin{array}{l}\text { (ASSAF NETO, } \\
2010)\end{array}$ & $K d_{i}=\frac{\text { Despesa } \text { Financeira }_{i}}{\text { Divida } \text { Total }_{i}}$ \\
\hline $\begin{array}{l}\text { Custo Médio Ponderado } \\
\text { de Capital (WACC) }\end{array}$ & $\begin{array}{l}\text { (ASSAF NETO, } \\
\text { 2010; DA- } \\
\text { MODARAN, } \\
\text { 2010) }\end{array}$ & WACC $=K e \times \frac{P L}{(P L+\text { Divida })}+K d \times \frac{\text { Divida }}{(P L+\text { Divida })}$ \\
\hline Variação de Preço $(\Delta \%)$ & $\begin{array}{l}\text { (DAMODARAN, } \\
\text { 2010). }\end{array}$ & $\Delta \%=\ln \left(\frac{P_{\mathrm{t}}}{P_{\mathrm{t}-1}}\right)$ \\
\hline
\end{tabular}




\begin{tabular}{|c|c|c|}
\hline Desvio padrão $(\sigma)(\sigma)$ & $\begin{array}{l}\text { (ASSAF NETO, } \\
2010)\end{array}$ & $\sigma_{i}=\sqrt{\frac{\sum_{i=1}^{n}\left(x_{i}-\bar{x}\right)^{2}}{(n-1)}}$ \\
\hline $\begin{array}{l}\text { Crescimento Líquido do } \\
\text { Investimento (CLI) }\end{array}$ & $\begin{array}{l}\text { (DAMODARAN, } \\
\text { 2010). }\end{array}$ & $\frac{C A P E X^{a}}{\text { Depreciação }}$ \\
\hline $\begin{array}{l}\text { Return on Investment } \\
(\mathrm{ROI})\end{array}$ & $\begin{array}{l}\text { I(DAMODARAN, } \\
\text { 2010). }\end{array}$ & $R O I=\frac{\text { NOPAT }}{\text { Investimento }}$ \\
\hline Return on Equity (ROE) & $\begin{array}{l}\text { (ASSAF NETO, } \\
\text { 2010).. }\end{array}$ & $R O E=R O I+(R O I-K d) \times \frac{\text { Dívida }}{P L}$ \\
\hline $\begin{array}{l}\text { Margem do Fluxo de Caixa } \\
\text { Operacional (MFCO) }\end{array}$ & $\begin{array}{l}\text { (ASSAF NETO, } \\
\text { 2010). }\end{array}$ & MFCO $=\frac{F C O}{\text { Receita }}$ \\
\hline Return on Sales (ROS) & $\begin{array}{l}\text { (DAMODARAN, } \\
\text { 2010). }\end{array}$ & ROS $=\frac{\text { Lucro Líquido }}{\text { Receita }}$ \\
\hline $\begin{array}{l}\text { Giro do Ativo ou do Inves- } \\
\text { timento (GI) }\end{array}$ & $\begin{array}{l}\text { (ASSAF NETO, } \\
\text { 2010). }\end{array}$ & $G I=\frac{\text { Receita }}{\text { Investimento }}$ \\
\hline Liquidez Corrente (LC) & $\begin{array}{l}\text { (ASSAF NETO, } \\
2010)\end{array}$ & $L C=\frac{A C}{P C}$ \\
\hline $\begin{array}{l}\text { Estrutura de Capital ou } \\
\text { Financiamento (EC) }\end{array}$ & $\begin{array}{l}\text { (ASSAF NETO, } \\
\text { 2010). }\end{array}$ & $E C=\frac{\text { Divida Total }}{\text { Investimento }}$ \\
\hline Cobertura de Dívidas (CD) & $\begin{array}{l}\text { (ASSAF NETO, } \\
\text { 2010). }\end{array}$ & $C D=\frac{\text { Despesas Financeiras }}{F C O}$ \\
\hline Equilíbrio Financeiro (EF) & (MATIAS, 2007). & $E F=\frac{(A C-P C)}{\text { Receita }}$ \\
\hline
\end{tabular}

Notas: ${ }^{a}$ Capital Expenditure $;{ }^{b}$ Net Operation Profit After Taxes

Fonte: Elaboração própria 